\section{A PHASE 1B/2 RANDOMIZED STUDY OF AVB-S6-500 IN COMBINATION WITH CABOZANTINIB VERSUS CABOZANTINIB ALONE IN PATIENTS WITH ADVANCED CLEAR CELL RENAL CELL CARCINOMA WHO HAVE RECEIVED FRONT-LINE TREATMENT} ${ }^{6}$ Hans Hammers, ${ }^{7}$ Matthew Campbell, ${ }^{8}$ Xin Gao, ${ }^{9}$ David McDermott, ${ }^{10}$ Randy Anderson, Vanessa Esquibel, ${ }^{10},{ }^{10}$ Eduardo Pennella, ${ }^{10}$ Reshma Rangwala, ${ }^{11}$ Eric Jonasch. ${ }^{1}$ VanderbiltIngram Cancer Center, Nashville, TN, USA; ${ }^{2}$ Comprehensive Cancer Centers of Nevada, Las Vegas, NV, USA; ${ }^{3}$ Allegheny Health Netword, Pittsburgh, PA, USA; ${ }^{4}$ Cleveland Clinic, Clevelenad, OH, USA; ${ }^{5}$ Memorial Sloan Kettering Cancer Center, New York, USA; ${ }^{6}$ University of Texas, Southwestern, Dallas, USA; ' University of Texas MD Anderson Ca Ctr, Houston, TX, USA; ${ }^{8}$ Massachusetts General Hospital, Boston, MA, USA; ${ }^{9}$ Beth Israel Deaconess Medical Center, Boston, MA, USA; ${ }^{10}$ Aravive, Inc., Houston, TX, USA; ${ }^{11}$ University of Texas, MD Anderson Ca Ctr, Houston, TX, USA

Background In clear cell renal cell carcinoma (ccRCC) the constitutive expression of hypoxia induced factor 1- $\alpha$ leads to increased expression of AXL. AXL overexpression has been associated with the development of resistance to VEGF inhibitors and suppression of the innate immune response through inhibition of macrophage-driven inflammation. AVB-S6-500 (AVB-500) is recombinant fusion protein dimer containing an extracellular region of human AXL combined with the human immunoglobulin G1 heavy chain $(\mathrm{Fc})$, which demonstrates highly potent, specific AXL inhibition. In mouse ccRCC xenograft models, AVB-500 showed significantly more tumor reduction in combination with pazopanib versus pazopanib alone. In a Ph1b study of AVB-500 plus chemotherapy in platinum-resistant ovarian cancer (NCT03639246), no dose limiting toxicity (DLT) or treatment discontinuation due to adverse events was observed. The recommended phase 2 dose (RP2D) of $15 \mathrm{mg} / \mathrm{kg}$ was established by a model-informed drug development (MIDD) approach.

\begin{tabular}{|c|c|c|c|}
\hline & $\begin{array}{l}\text { Prior lines of therapy in the } \\
\text { advanced/metastatic setting }\end{array}$ & $\begin{array}{l}\# \text { Cycles } \\
\text { completed }\end{array}$ & $\begin{array}{l}\text { Best overall } \\
\text { response }\end{array}$ \\
\hline $102-001$ & $\begin{array}{l}\text { 1) Nivolumab/ipilimumab } \\
\text { 2) Axitinib } \\
\text { 3) }\end{array}$ & $\begin{array}{c}1.5 \\
\text { discontinued } \\
\text { study }\end{array}$ & SD \\
\hline $102-002$ & $\begin{array}{l}\text { 1) Pazopanib } \\
\text { 2) Pembrolizumab/axitinib }\end{array}$ & 3 , ongoing & SD \\
\hline 103-001 & 1) Nivolumab/ipilimumab & 4 , ongoing & $\mathrm{PR}$, unconfirmed \\
\hline $105-002$ & 1) Sunitinib 2) Nivolumab & 2 , ongoing & PR, unconfirmed \\
\hline $107-002$ & $\begin{array}{l}\text { 1) Pazopanib } \\
\text { 2) Everolimus } \\
\text { 3) Axitinib } \\
\text { 4) Nivolumab/ipilimumab } \\
\text { 5) Pembrolizumab/axitinib (Best } \\
\text { response to therapy PD) }\end{array}$ & 2 , ongoing & $\mathrm{PR}$, unconfirmed \\
\hline
\end{tabular}

Methods The P1b portion of this trial is a $3+3$ dose escalation study to evaluate safety, pharmacokinetics, and pharmacodynamics of AVB 500 in combination with cabozantinib 60 mg daily. Dose levels of AVB-500 may include 15, 20, and 25 $\mathrm{mg} / \mathrm{kg}$ every two weeks. The primary objective is to evaluate safety and tolerability. Secondary objectives include identification of the RP2D of AVB-500 and clinical activity. Key eligibility criteria include clear cell histology RCC and at least one prior line of therapy administered in the advanced or metastatic setting.

Results As of July 21, 2021, seven patients have received at least one dose of AVB-500 $15 \mathrm{mg} / \mathrm{kg}$ and cabozantinib, with six patients ongoing treatment. No DLTs were observed. Trough levels at C1D15 were above the minimally efficacious concentration (MEC) identified from MIDD and GAS6 (AXL ligand) levels were suppressed prior to C2D1. Partial responses were observed in 3 of 5 patients (table 1); all patients demonstrated tumor decrease from baseline.

Conclusions AVB-500 in combination with cabozantanib demonstrates promising preliminary clinical activity and tolerability in patients with ccRCC. AVB-500 $15 \mathrm{mg} / \mathrm{kg}$ is the presumptive RP2D with C1D15 AVB-500 troughs consistently above MECs observed. Safety, PK/PD and clinical activity will be updated at the time of presentation. (NCT04300140)

Ethics Approval This study has obtained ethics approval from WIRB Institutional Review Board ${ }^{\circledR}$, Protocol ID \#20200159, and all subjects provided informed consent prior to taking part in this study.

http://dx.doi.org/10.1136/jitc-2021-SITC2021.424 